\title{
Biomonitoramento do potencial do risco genotóxico e análise físico-química da água do Balneário Veneza no município de Caxias-MA
}

\author{
Biomonitoring of genotoxic risk potential and physicochemical analysis of water at Balneário \\ Veneza in the city of Caxias-MA \\ Biomonitoreo del potencial de riesgo genotóxico y análisis fisicoquímico del agua en Balneário \\ Veneza en la ciudad de Caxias-MA
}

Recebido: 19/11/2021 | Revisado: 28/11/2021 | Aceito: 01/12/2021 | Publicado: 12/12/2021

\author{
Manoel Vyctor Rocha da Silva \\ ORCID: https://orcid.org/0000-0002-3460-8597 \\ Universidade Estadual do Maranhão. Brasil \\ E-mail: manoelrocha118@gmail.com \\ Deuzuita dos Santos Freitas Viana \\ ORCID: https://orcid.org/0000-0002-1902-6505 \\ Universidade Estadual do Maranhão, Brasil \\ E-mail: deuzuitasfv@gmail.com
}

\begin{abstract}
Resumo
Com o exagerado aumento de poluição, resultante das ações antrópicas, no ambiente aquático é evidente a importância do uso do biomonitoramento para a verificação de agentes tóxicos, citotóxicos e genotóxicos. Portanto, esta pesquisa objetivou analisar a qualidade das águas do Balneário Veneza na zona urbana de Caxias-MA, através de análises físico-químicas e genotóxicas. Para a coleta das amostras das águas foram escolhidos cinco pontos de mediante a intensificação de banhistas e pontos que não há indícios de banhistas. Os pontos foram descritos em P1, P2, P3, P4 e P5, atingindo as extremidades do Balneário. As amostras das águas foram levadas ao Laboratório de Físico-química do SAAE (Serviço Autônomo de Água e Esgoto), para as análises físico-químicas. Posteriormente foram realizados os testes genotóxicos utilizando o bioensaio Trad -MCN. Observou-se durante toda a extensão da lagoa focos visíveis de poluição de natureza antrópica, mostrou também uma quantidade elevada de macrófitas, especialmente em P1, nos demais pontos, além da intensificação de banhistas, a água da lagoa se mostrou com uma coloração opaca. Nas análises químicas a dureza e o ferro foram os parâmetros em desconformidade com o valor máximo permitido na Portaria 05/2017 do Ministério da Saúde. Os testes genotóxicos não mostraram alterações cromossômicas nas tétrades inferindo que a água do Balneário não possui substâncias genotóxicas.
\end{abstract}

Palavras-chave: Bioindicador; Poluição Hídrica; Trad-MCN.

\begin{abstract}
With the exaggerated increase in pollution resulting from anthropic actions in the aquatic environment, the importance of using biomonitoring to verify toxic, cytotoxic and genotoxic agents is evident. Therefore, this research aimed to analyze the water quality of Balneário Veneza in the urban area of Caxias-MA, through physical-chemical and genotoxic analyses. For the collection of water samples, five points were chosen through the intensification of bathers and points where there is no evidence of bathers. The points were described in P1, P2, P3, P4 and P5, reaching the ends of the Spa. The water samples were taken to the Physical-Chemistry Laboratory of the SAAE (Autonomous Water and Sewage Service) for physical-chemical analyses. Subsequently, genotoxic tests were performed using the Trad-MCN bioassay. Visible sources of anthropogenic pollution were observed along the entire length of the lake, it also showed a high amount of macrophytes, especially in P1, in the other points, in addition to the intensification of bathers, the water in the lake showed an opaque color. In the chemical analysis, hardness and iron were the parameters that did not comply with the maximum value allowed in Ordinance 05/2017 of the Ministry of Health. The genotoxic tests did not show chromosomal alterations in the tetrads, inferring that the spa water does not have genotoxic substances.
\end{abstract}

Keywords: Bioindicator; Water pollution; Trad-MCN.

\section{Resumen}

Con el aumento exagerado de la contaminación resultante de las acciones antrópicas en el medio acuático, se evidencia la importancia de utilizar el biomonitoreo para verificar agentes tóxicos, citotóxicos y genotóxicos. Por tanto, esta investigación tuvo como objetivo analizar la calidad del agua del Balneario Veneza en el casco urbano de Caxias-MA, a través de análisis físico-químicos y genotóxicos. Para la recogida de muestras de agua se eligieron 
cinco puntos mediante la intensificación de bañistas y puntos donde no hay constancia de bañistas. Los puntos fueron descritos en P1, P2, P3, P4 y P5, llegando a los extremos del Balneario. Las muestras de agua se llevaron al Laboratorio de Físico-Química del SAAE (Servicio Autónomo de Agua y Saneamiento) para análisis físico-químicos. Posteriormente, se realizaron pruebas genotóxicas mediante el bioensayo Trad-MCN. Se observaron fuentes visibles de contaminación antropogénica a lo largo de toda la extensión del lago, también mostró una alta cantidad de macrófitas, especialmente en P1, en los demás puntos, además de la intensificación de bañistas, el agua en el lago mostró un color opaco. En el análisis químico, la dureza y el hierro fueron los parámetros que no cumplieron con el valor máximo permitido en la Ordenanza 05/2017 del Ministerio de Salud. Las pruebas genotóxicas no mostraron alteraciones cromosómicas en las tétradas, infiriendo que el agua del balneario no tienen sustancias genotóxicas.

Palabras clave: Bioindicador; Contaminación del agua; Trad-MCN.

\section{Introdução}

As ações antrópicas causam imensos prejuízos no ambiente e influencia diretamente na propriedade das águas naturais e na perda da biodiversidade aquática. Os fatores urbanos tais como, poluição industrial e doméstica, elevam gradualmente o impacto ambiental e por sua vez, acabam por comprometer a qualidade do recurso hídrico (Ferreira et al., 2019). Os principais impactos da progressão de uma rede urbana em relação as redes hidrográficas estão intimamente ligados à sua forma de ocupação, no que se refere à falta de sistema de serviços públicos, saneamento básico, no processo de implantação (Sampaio \& Gomes, 2020).

Muitos poluentes no meio ambiente, como as substâncias ou materiais para os quais a água pode ser a principal via de transporte, em um estado ecológico poluído ou contaminado, ela pode representar problemas à saúde (Boelee et al., 2019). Vale ressaltar também, que o uso da água para fins de lazer e higiene pela população é um grande fator da degradação dos recursos hídricos.

A poluição da água leva à formação e acúmulo de misturas complexas com potenciais tóxicos e genotóxicos. Além disso, processos de bioacumulação são potencialmente prejudiciais a diversas estruturas celulares, como membranas plasmáticas, mitocôndria, lisossomos e o próprio DNA (Boelee et al., 2019). Índices elevados de ferro, causada pela ação humana, pode ocasionar sérios problemas de saúde para a população que faz o desfrute da água do Balneário. No caso da toxicidade em seres humanos, quantidades elevadas de ferro no organismo se relacionam a diversas patologias, bem como enfermidades hepáticas e cardíacas, diabetes, anormalidades hormonais, doenças neurodegenerativas como o alzheimer, câncer, e anormalidades do sistema imune (Prá, 2008).

Com o aumento de poluição, resultante das ações do homem, no ambiente aquático é evidente a importância do uso do biomonitoramento para a verificação de agentes que possam causar alterações, tóxicas, citotóxicas e genotóxicas. O biomonitoramento é uma ferramenta que tem por fundamento avaliar os efeitos e mostrar informações relevantes sobre o impacto dos poluentes no meio ambiente através de bioindicadores.

Os atuais avanços no campo da ecotoxicologia mostram uma variedade de biomarcadores que são usados para aferir a exibição a produtos químicos em organismos (Araújo et al., 2018). Para Santos, (2019) um bioindicador tem a característica de quantificar alterações ambientais, por acúmulo de elementos em seu interior.

Dentre os vegetais mais utilizados como bioindicador, está a Tradescantia pallida purpúrea. A morfologia e a fisiologia da $T$. pallida garante um maior aproveitamento para a análise da toxicidade nas suas estruturas, verificando com mais rapidez e facilidade as alterações que os agentes mutagênicos causam em seu organismo. Estes agentes mutagênicos geralmente são provenientes de elementos físicos e químicos que podem alterar o código genético do organismo (Santos, 2019).

Com o surgimento de métodos analíticos mais sensíveis, os contaminantes vêm sendo detectados nos meios aquáticos e são considerados um problema eminente, de forma que há um aumento do consumo pela sociedade dos produtos que são 
fontes de poluição (Andrade, Ferreira, 2017). O bioensaio Trad-MCN (Teste de Micronúcleo em Tradescantia pallida) é usado para a verificação dos efeitos mutagênicos que estressores externos causam no vegetal.

Dessa forma, esta pesquisa objetivou analisar a qualidade das águas do Balneário Veneza na zona urbana de CaxiasMA, através de análises físico-químicas e genotóxicas.

\section{Metodologia}

Este estudo possui uma abordagem experimental, e segundo Ferreira, (2005), o desenvolvimento de pesquisas experimentais tornam-se meios importantes na medida em que estes ajudam no entendimento dos fenômenos que ocorrem no meio.

O Balneário Veneza (Figura 1) fica localizado na zona urbana da cidade de Caxias - MA e concentra diariamente em suas dependências banhistas das regiões circunvizinhas e genuínos.

Figure 1: Balneário Veneza, Caxias - MA. (A) Via satélite. (B) Visto pelo ângulo dos banhistas.

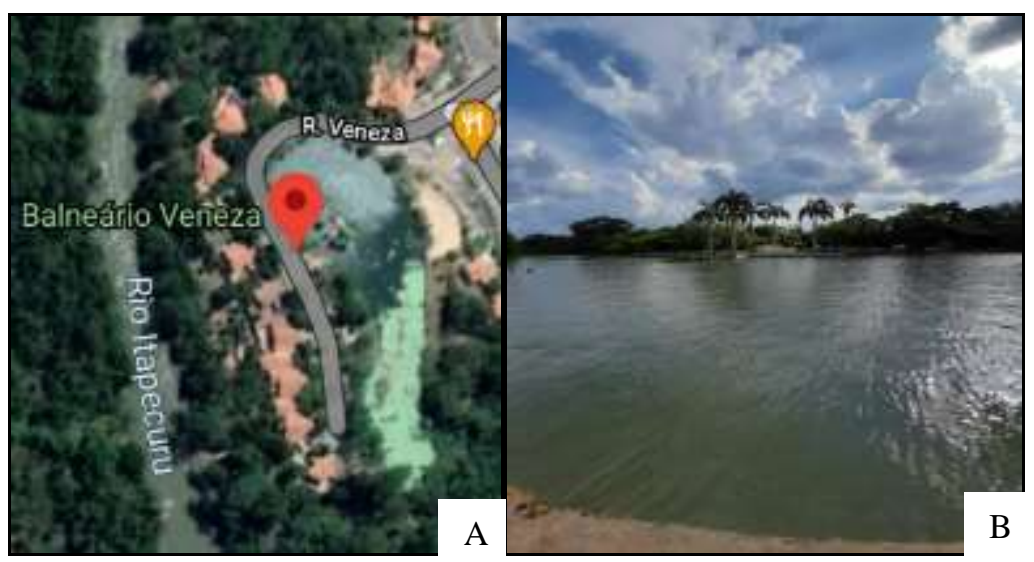

Fonte: (A) Google Maps, 2021; (B) Dados da pesquisa (2021).

\subsection{Amostragem e Análise físico-química.}

Foram escolhidos cinco pontos do Balneário, mediante a intensificação de banhistas e pontos que não há indícios de banhistas, no qual as amostras foram colhidas. Os pontos foram descritos em P1, P2, P3, P4 e P5, atingindo as duas margens da lagoa. As amostras das águas foram colhidas em frascos com volume de $1200 \mathrm{ml}$, identificou-se cada frasco com uma ficha contendo as informações como, coletor, fonte, descrição da amostra e horário. A figura 2 mostra a realização da coleta e as amostras nos coletores identificados.

Figure 2: (A) Realização da coleta das amostras das águas. (B) Amostras colhidas e identificadas.

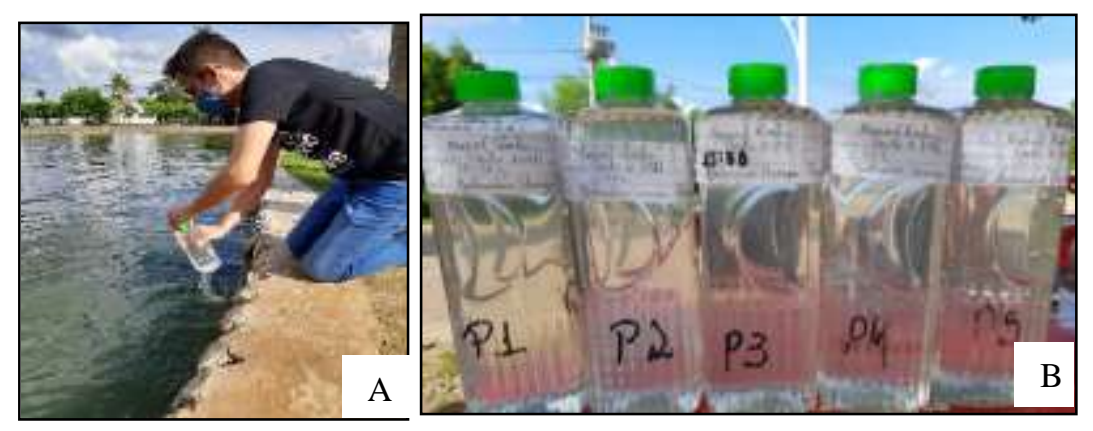

Fonte: Dados da pesquisa (2021). 
Logo após as coletas, as amostras foram levadas ao Laboratório de físico-química do SAAE (Serviço Autônomo de Água e Esgoto) da cidade de Caxias-MA. Para o monitoramento de qualidade da água, onde foram realizadas análises físicoquímicas, foram vistos os seguintes parâmetros: Turbidez, Cor, pH, Cloro, Fluoretos, Alcalinidade Total, CO 2, Dureza, Cloreto, Alumínio, Ferro, Amônia, Nitrato, Nitrito, Sulfato, Manganês, Sulfeto, Surfactantes, Fenol, Zinco, Cromo, Cobre e Condutividade.

\subsection{Biomonitoramento e Bioensaio Trad-MCN}

O biomonitoramento da qualidade da água da lagoa do Balneário Veneza em Caxias-MA foi realizado com a planta bioindicadora T. pallida purpúrea. O grupo controle nesta etapa do estudo utilizou água não poluída.

As inflorescências jovens da $T$. pallida são as mais indicadas para a verificação de micronúcleos, por apresentarem células em estágio de tétrade em botões de estágio intermediário. O botão escolhido foi dissecado e posteriormente macerado e colocado uma gota de carmim acético $2 \%$, devendo ser retirado todos os "debris" (fragmentos celulares resultantes da maceração do botão) antes de colocar a lamínula.

Após a coleta e intoxicação das inflorescências, acontece a fixação dos botões florais em um frasco bem vedado contendo solução de Carnoy durante 24 horas, em seguida, os botões são transferidos para outro frasco contendo álcool 70\%. E logo após os botões são retirados com auxílio de uma pinça segundo o protocolo de (Peres et al., 2010).

Após 24 horas de fixação dos botões inicia-se então o preparo da lâmina. Primeiramente é selecionado o botão floral que há células em fase de tétrade, do terceiro ao quinto botão floral, seguindo uma ordem crescente de tamanho para a seleção

Foram retiradas as células mãe do grão de pólen que ficam presentes dentro de uma membrana no botão e que serão maceradas em lâminas para microscópio por meio de auxílio de estilete e/ou pinça metálica com uma gota de carmim acético $2 \%$, após, é coberto com uma lamínula. A lâmina é aquecida utilizando uma lamparina de vidro a álcool com tampa e pavio $\left(80^{\circ} \mathrm{C}\right)$. Pressiona-se com a mão sobre a lamínula para maior fixação na lâmina de acordo com a metodologia de (Yaguinuma et al., 2014).

Após todo o processo de fixação dos botões, foi realizada a avaliação da genotoxicidade causada na T. pallida, submetendo a lamina preparada em um microscópio óptico para leitura da frequência de micronúcleo de acordo com o potencial agente contaminante selecionado para o estudo de acordo com (Peres et al., 2010).

\section{Resultados e Discussão}

Foram observados na lagoa do Balneário Veneza, uma alta quantidade de macrófitas, principalmente em P1, além de mostrar também os descartes de resíduos de natureza antrópica na extensão da lagoa (Figura 3), o que pode vir à ocasionar alterações no meio. 
Figure 3: Representação dos pontos escolhidos. (A) Ponto com quantidade considerável de Macrófitas. (B e C) Pontos com a coloração dá água opaca.

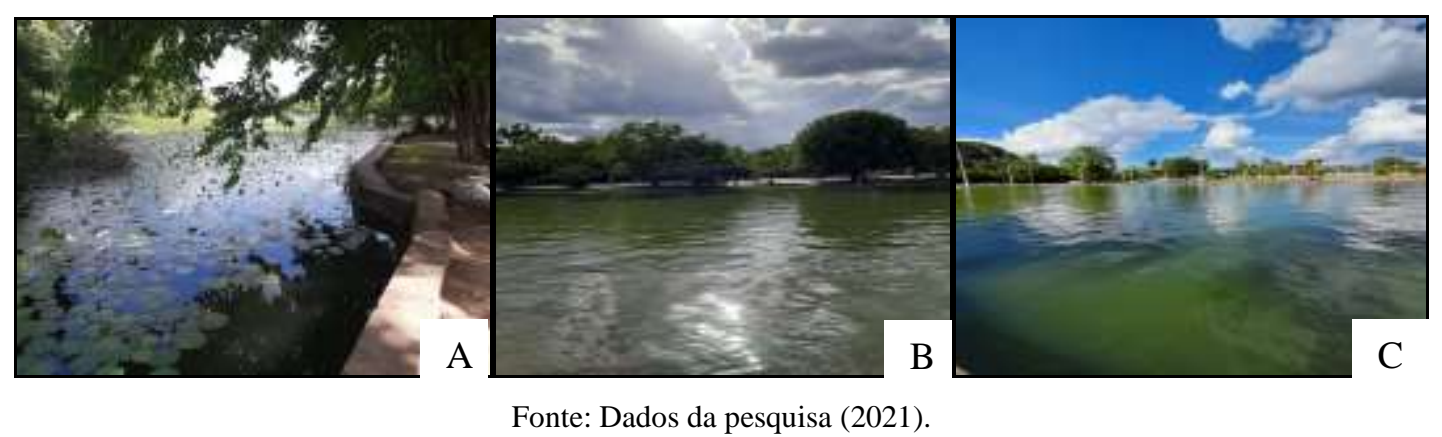

A análise físico-química da água realizada mostrou desconformidades em alguns parâmetros, de acordo com a Portaria 05/2017 do Ministério da Saúde. De todos os parâmetros analisados, Dureza e Ferro foram os únicos que se encontraram em desconformidade, sendo Dureza alterada em todos os pontos e Ferro em P2 e P3, os valores das alterações desses parâmetros estão descritos na Tabela 1.

Tabela 1: Resultados para Dureza e Ferro nas águas coletadas em cinco pontos selecionados do Balneário Veneza em CaxiasMA.

\begin{tabular}{ccccccc}
\hline PARÂMETRO & P1 & P2 & P3 & P4 & P5 & $\begin{array}{c}\text { PORTARIA N } \\
\text { 05/2017 (V.M.P) } \\
*\end{array}$ \\
\hline DUREZA & 566,00 & 554,00 & 542,00 & 552,00 & 558,00 & $500 \mathrm{mg} / \mathrm{L}$ \\
\hline FERRO & - & 0,32 & 0,37 & - & - & $0,3 \mathrm{mg} / \mathrm{L}$ \\
\hline
\end{tabular}

V.M.P (Valor Máximo Permitido). Fonte: Laboratório de Físico-química do SAAE (Serviço Autônomo de Água e Esgoto) (2021). *

As avaliações das caracterizações da água servem verificar os índices da qualidade da água, esses índices podem ser de ordens físicas, químicas e biológicas (Fay \& Silva, 2006).

Segundo Von Sperling (2007), a dissolução de minerais contendo cálcio e magnésio, como as rochas calcárias e os despejos industriais entre outros, são as principais fontes de dureza.

Um dos principais fatores da elevação de ferro na água é a contaminação antrópica, ou seja, causada pela ação humana. A alteração de Ferro na água pode ocasionar sérios problemas de saúde para a população que faz o desfrute da água do Balneário. No caso da toxicidade em seres humanos, quantidades elevadas de ferro no organismo se relacionam a diversas patologias, bem como doenças hepáticas e cardíacas, diabetes, anormalidades hormonais, doenças neurodegenerativas como o alzheimer, câncer, e anormalidades do sistema imune (Prá, 2008).

Outros parâmetros observados não mostraram desconformidades, entretanto seus valores variavam de forma crescente e outros se mostraram estáveis a cada ponto. A Tabela 2 mostra os valores de cada um desses parâmetros. 
Tabela 2: Resultados para Cor, Sulfato e Condutividade nas águas coletadas em cinco pontos selecionados do Balneário Veneza em Caxias-MA

\begin{tabular}{ccccccc}
\hline PARÂMETRO & P1 & P2 & P3 & P4 & P5 & $\begin{array}{c}\text { PORTARIA N }^{\mathbf{0 5} / 2017}(\text { V.M.P)* } \\
\end{array}$ \\
COR & 8,00 & 8,00 & 7,00 & 7,00 & 7,00 & $15,0(\mathrm{uH})$ \\
\hline SULFATO & 218,00 & 190,00 & 244,00 & 202,00 & 206,00 & $250 \mathrm{mg} / \mathrm{L}$ \\
\hline CONDUTIVIDADE & 698,90 & 825,00 & 846,00 & 848,20 & 844,50 & $\mu \mathrm{S} / \mathrm{cm}$ \\
\hline
\end{tabular}

*V.M.P (Valor Máximo Permitido). Fonte: Laboratório de Físico-química do SAAE (Serviço Autônomo de Água e Esgoto), 2021.

Vale ressaltar que a Turbidez só mostrou alteração em P3, que obteve como resultado 1,04 uT, quando o V.M.P é 1,0 uT. Segundo Almeida et al., (2017), dizem que a alteração da Turbidez pode ocorrer após períodos de chuvas intensas, destacase que as coletas das amostras se deram em fevereiro de 2021, em um período chuvoso. E essa alteração pode estar intrinsicamente ligada com os parâmetros Cor e pH.

A cor traz indicadores de alterações no meio que possa estar influenciando a propriedade da água como, a lavagem do solo e carreamento de sólidos dissolvidos para água, influenciando na transparência da água (Souza et al., 2020).

O sulfato, nas concentrações normalmente observadas em águas, não é tóxico. Porém, sua redução a sulfeto pode inibir o processo anaeróbio (Paula Jr. \& Foresti, 2009). A preocupação na presença de sulfato elevada, é ocasionar a diminuição do sulfeto. Para a Resolução 357/05 do CONAMA estabelece um limite de 250 mg/L para o Sulfato,

A condutividade é um parâmetro que destaca mudanças no arranjo dos corpos d'água, em contrapartida não alude quantidades e componentes, mas é um parâmetro de extrema relevância para controlar e determinar o estado e a qualidade de água (Piratoba et al., 2017). A condutividade fornece uma boa indicação das mudanças na conformação da água, mas não fornece indicação das quantidades dos vários componentes, entretanto, altos valores podem indicar características corrosivas da água (Cetesb, 2016).

\subsection{Análise genotóxica}

As inflorescências escolhidas (Figura 4) foram submetidas ao processo de intoxicação nas águas coletadas e em seguida ao processo de fixação na Solução Carnoy.

Figure 4: Inflorescências escolhidas para a primeira parte do Bioensaio Trad - MCN.

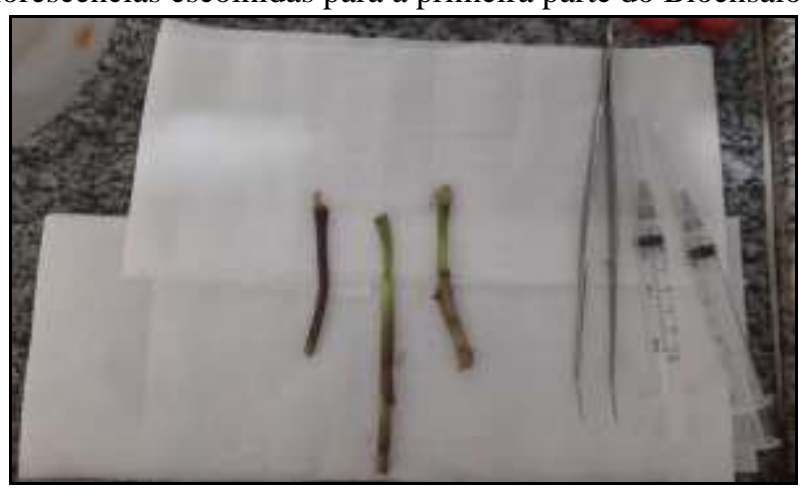

Fonte: Dados da pesquisa (2021).

No bioensaio Trad-MCN, não foram encontrados micronúcleos e alterações cromossômicas nas tétrades. Em vários estudos científicos o ensaio Trad-MCN tem sido utilizado e possui inúmeras vantagens em relação aos métodos padronizados 
para a determinação de níveis de agentes contaminantes. O ensaio Trad-MCN possui baixo custo, material de amostra de fácil acesso e maior sensibilidade, a resposta dos testes aos poluentes fornece uma indicação confiável da qualidade e das características do meio ambiente (Costa et al., 2016).

Segundo Morais et al., (2016), consideram que o uso de organismos como bioindicadores seja de extrema relevância para indicar riscos de exposição a poluentes. Para Malaman et al. (2020), em certos casos não é factível mensurar o impacto ambiental da água apenas com as avaliações físico-químicos. Dessa forma é importante à realização de testes de citogenotoxicidade e mutagenicidade como estudos complementares a demais testes.

\section{Conclusão}

Observou-se durante toda a extensão da lagoa do Balneário focos visíveis de poluição de natureza antrópica. Mostrou também uma quantidade elevada de macrófitas, especialmente em P1. Nos demais pontos além da intensificação de banhistas a água da lagoa se mostrou com uma coloração opaca. As principais alterações nos parâmetros físico-químicos vistos, foram nos parâmetros dureza e ferro. O alto teor de ferro na água pode ocasionar patologias tais como doenças hepáticas e cardíacas, câncer, e anormalidades do sistema imune nos seres humanos.

Os testes genotóxicos não mostraram micronúcleos e alterações cromossômicas nas tétrades inferindo que a água do Balneário não possui substâncias genotóxicas para os seres vivos. No entanto, não significa que a água não possua substâncias tóxicas. Estudos relacionados ao biomonitoramento são importantes, tendo em visto que este é um método para a verificação da qualidade da água pois dar uma ideia aos riscos que a população estar exposta e mostra a necessidade de preservar e conservar os recursos hídricos, como pode dar subsídios para as pesquisas futuras no âmbito do monitoramento da poluição da água.

\section{Referências}

Almeida, M. C., Silva, M. M. \& Paula, M. de. (2017). Avaliação do desempenho de uma estação de tratamento de água em relação à turbidez, cor e pH da água. Revista Eletrônica de Gestão e Tecnologias Ambientais (GESTA), 5(1), 25- 40.

Andrade, M. C. K. \& Ferreira, R. L. (2017). Determinação de contaminantes emergentes no rio barigui em curitiba/paraná. Revista Saúde e Desenvolvimento, $11(8), 27-28$.

Araújo, F. G., Morado, C. N., Parente, T. T. E., Paumgartten, F. J. R. \& Gomes, I. D. (2018). Biomarkers and bioindicators of the environmental condition using a fish species (Pimelodus maculatus Lacepède, 1803) in a tropical reservoir in Southeastern Brazil. Brazilian Journal of Biology, 78(2), 351-359.

Boelee, E.; Geerling, G., Van Der Zaan, B., Blauw, A. \& Vethaak, A. D. (2019). Water and health: From environmental pressures to integrated responses. Acta Tropica, (193), 217-226.

Brasil, (2005). Conselho Nacional do Meio Ambiente - Conama Resolução 357/2005, Enquadramento dos Corpos Hídricos Superficiais no Brasil. Governo Federal, Brasília. Publicada no DOU n 53, de 18 de março, Seção 1, 58-63.

CETESB. (2016). Significado Ambiental e Sanitário das Variáveis de Qualidade das Águas e dos Sedimentos e Metodologias Analíticas e de AmostragemApêndice E. ompanhia Ambiental do Estado de São Paulo - CETESB. Https: // cetesb. sp.gov.br/aguas-interiores/wpcontent/uploads/sites/12/2017/11/Ap\%C3\%AAndice-E-Significado-Ambiental-e-Sanit\%C3\%A1rio-das-Vari\%C3\% A1veis-de-Qualidade-2016.pdf.

Da Costa, G. M., Petry, C. T., \& Droste, A. (2016). Active versus passive biomonitoring of air quality: genetic damage and bioaccumulation of trace elements in flower buds of Tradescantia pallida var. purpurea. Water, Air, \& Soil Pollution, 227(7), 1-12.

de Souza, D. F., da Silva, L. D. O. S., \& Pinto, A. L. (2020). Qualidade física, química e biológica sazonal das águas superficiais da bacia hidrográfica do córrego Moeda em Três Lagoas/MS. Revista Brasileira de Geografia Física, 13(01), 196-210.

Fay, E. F. \& Silva, C. M. M. S. (2006). Índice de uso sustentável da água (ISA - Água) na região do sub - médio São Francisco. 1. ed. Jaguariúna: Embrapa Meio Ambiente, 157.

Ferreira, L. M., Hochman, B., \& Barbosa, M. V. J. (2005). Modelos experimentais em pesquisa. Acta Cirurgica Brasileira, $20,28$.

Ferreira, A. S., Gonçalves, G. H., Bizeto, L., Moura, C. \& Rocha-Lima, A. B. C. (2019) Análise de águas destinadas à recreação de contato primário (cachoeira Guaxinduva) utilizando Tradescantia pallida como bioindicador de genotoxicidade. Unisanta Bioscience, 8(3), 262-270. 
Research, Society and Development, v. 10, n. 16, e238101623569, 2021

(CC BY 4.0) | ISSN 2525-3409 | DOI: http://dx.doi.org/10.33448/rsd-v10i16.23569

Gorni, P. H., Guandalini, C. R., da Silveira, Z. V., \& Nakayama, F. T. (2014). Effect of tannery sludge in micronucleus frequency in bioindicator Tradescantia pallida (Rose) DR Hunt var. purpurea. Revista Brasileira de Engenharia de Biossistemas, 8(4), 361-373.

Malaman, A. C. P., Fluminhan Junior, A., Silva, W. L., Santos, I. F. \& Silva, P. A. (2020). Citogenotoxicidade de águas fluviais urbanas em Presidente Prudente (SP), Brasil, através do teste Allium cepa. Revista Ibero Americana de Ciências Ambientais, 11(2), 249-265.

Morais. C. R., Carvalho, S. M., Araujo, G. R., Souto, H. N., Bonetti, A. M., Morelli, S. \& Campos Júnior, E. O. (2016). Assessment of water quality and genotoxic impact by toxic metals in Geophagus brasiliensis. Chemosphere, 152, 328-334.

Paula Jr., D.R. \& Foresti, E. (2009) Sulfide toxicity kinetics of a UASB reactor. Brazilian Journal of Chemical Engineering, 26(4), 669-675.

Peres, W. L., Lira, O. F. C., Costa, K. A. (2010). Biomonitoramento com Tradescantia pallida em Mato Grosso. Monografia (Especialização). Universidade de São Paulo. Faculdade de Medicina. Especialização em Poluição do Ar e Saúde Humana. 81.

Piratoba, A. R. A.; Ribeiro, H. M. C.; Morales, G. P.; Gonçalves, W. G. (2017). Caracterização de parâmetros de qualidade da água na área portuária de Barcarena, PA, Brasil. Revista Ambiente \& Água, 12(3), 435-456.

Prá, D. (2008). Ferro e estabilidade genômica: uma análise nutrigenômica dos efeitos da deficiência e da sobrecarga. Tese de Doutorado, Universidade Federal do Rio Grande do Sul, Porto Alegre, RS, Brasil, 13.

Sampaio, S. A., \& Gomes, R. L. (2020). O saneamento básico de ipiaú e sua influência na qualidade das águas do rio de contas. Caminhos de Geografia, 21(74), 68-86.

Santos, N. B. et al. (2019). Utilização de Tradescantia pallida purpurea como bioindicadora de agentes tóxicos na água. Unisanta BioScience, 8(3), 326-336.

Von Sperling, M. (2007). Estudos de modelagem da qualidade da água de rios. UFMG, 7, 452.

Yaguinuma, D. H., Brito, L. G. L. \& Fluminhan, A. (2014). Avaliação dos danos genéticos provocados por radiação solar e poluição aérea através da análise de micronúcleos em Tradescantia pallida cv purpurea. Periódico Eletrônico Fórum Ambiental da Alta Paulista, Tupã - SP. 10(12). 